\title{
Legalmente necessários,
} socialmente (in) desejados: imigrantes brasileiros no mercado de
trabalho japonês

\author{
Katiani Tatie Shishito * \\ Mariana Shinohara Roncato **
}

\section{Introdução ${ }^{1}$}

No contexto das migrações internacionais contemporâneas, a imigração de brasileiros no Japão ficou conhecida como "imigração dekassegui", sendo que a raiz dessa palavra japonesa está intimamente relacionada com o mundo do trabalho. $\mathrm{O}$ termo dekassegui (出稼ぎ) tem sua origem no substantivo japonês que é derivado de dois verbos: deru (出る)-sair e kasegu (稼ぐ) - ato de ganhar dinheiro através do trabalho, designando assim a pessoa que sai de sua terra de origem para trabalhar por um determinado período em outro lugar. Tal como sua origem etimológica, o fenômeno social da imigração dekassegui também está estreitamente ligado ao mundo do trabalho e sua análise, portanto, não poderia se dissociar da compreensão das relações deste, bem como das políticas migratórias decorrentes da conjuntura econômica e social do Japão.

Entendemos igualmente que a complexidade deste fenômeno, muito além das políticas migratórias e do mundo do trabalho, abarca diversas questões relevantes, tais como temas referentes à identidade, memória, família, gênero, educação, preconceitos/xenofobia, entre outras importantes problemáticas. No entanto, neste artigo, apresentamos uma discussão que relaciona principalmente trabalho e política migratória. Esta relação é feita mediante exposição cronológica dos acontecimentos que consideramos pertinentes para compreensão, tanto do cenário do mundo do trabalho japonês quanto da inserção do imigrante dekassegui no Japão.

Para analisar a dinâmica das Políticas de Controle de Imigração utilizamos as publicações documentais do Immigration Bureau ligado ao Ministério da Justiça

\footnotetext{
* Doutoranda no Departamento de Demografia/IFCH/NEPO da UNICAMP. Contato: katishishito@hotmail.com

** Doutoranda no Departamento de Sociologia/IFCH da UNICAMP. Contato:mari_roncato@ yahoo.com.br
} 
do Japão. Atenção particular é voltada ao modo como essas políticas tiveram reflexo na imigração de brasileiros naquele país e como o mundo do trabalho está estreitamente relacionado a esta dinâmica. No que concerne a análise das relações de trabalho, utilizamos os dados do Ministério da Saúde, Trabalho e BemEstar Social (Kousei Roudoushō), com enfoque nas principais transformações e flexibilizações nas relações contratuais que atingem diretamente a classe trabalhadora.

\section{Do país fechado à segunda potencia mundial}

Diferentemente de países da Europa, dos Estados Unidos ou do Brasil, o Japão não tem uma tradição consolidada em receber imigrantes. Em seu feudalismo houve um período de auto isolamento conhecido como Sakoku², no qual o Japão interrompeu todo intercâmbio com outros países, exceto uma parcial abertura para comércio com a Holanda, Coreia e China. Este período de Sakoku teve uma duração consideravelmente longa entre os anos de 1639-1854. As mudanças para abertura do relacionamento com outras nações só aconteceram com a Restauração Meiji, em 1868. Oficialmente, somente após o decreto no ano de 1899, chamado Naichi Zakkyo ${ }^{3}$, é que foi promulgada a abertura do país ao comércio, assim como abolidas as restrições para a permanência, residência e livre circulação de imigrantes em solo japonês.

A reforma política e social da Restauração Meiji foi liderada pela nova elite japonesa, que se configurou com a implantação de um sistema social moderno, que implicava em um Estado centralizado, numa economia industrial e em um sistema colônia que ocorreu na região asiática com as Guerras Sino-Japonesa (nichuu-sensou), Guerra Russo-Japonesa (Nichiro-sensou, 1905) e Ocupação japonesa na Coreia (ODA, 2011. p.106). A ideia de nação japonesa, portanto, reforçada na era Meiji é construída através da necessidade de um Estado forte (o Estado-Nação) que, para isso (tal como aconteceu na Europa), requer a criação da ideia de homogeneidade étnica, mesmo que construída artificialmente (ASADA, 2001, p.37). Dessa maneira, embora no Brasil tenha se tornado recorrente a imagem atribuída aos japoneses, enquanto pertencentes a uma cultura milenar de um povo étnico homogêneo, a ideia socialmente construída de uma base cultural comum a toda nação japonesa é recente (ODA, 2011).

O período que se segue, é marcado pela derrota do Japão na II Guerra Mundial e as transformações no país decorrente deste marco histórico. Logo após a derrota, o país foi ocupado pelos Estados Unidos e sofreu mudanças intensas, tanto do ponto de vista geopolítico (o "grande império japonês" foi diminuído consideravelmente), demográfico (implicando num movimento de migrações entre ex-metrópole e ex-colônias), e da própria administração governamental e de defesa do Japão que ficou por conta da intervenção dos Estados Unidos (ODA, 2011). Essas mudanças tiveram efeito significativo sobre as políticas de controle migratório, agora definidas pelos Estados Unidos ${ }^{4}$. 
O momento seguinte, especialmente depois da II Guerra Mundial até a década de 1980, geralmente é associado à inexistência da presença de imigrantes. Segundo a pesquisadora da história japonesa Morris-Suzuki (2006, p.3), alguns estudos apontam que o Japão teve um crescimento econômico no Pós-Guerra sem a presença de imigrantes . Conforme sua compreensão, tal perspectiva criaria um espaço em branco (blank space) da história e memória do Japão que ignorou a presença destes imigrantes invisíveis (Invisible Immigrants) .

Segundo Morris-Suzuki (2006), ainda que houvesse uma carência de dados estatísticos em relação a imigração, não podemos dizer que não existiam imigrantes em solo japonês durante aquele período. Esta autora se apropria de diversos relatos, assim como de alguns dados referentes à imigração indocumentada e prisões de imigrantes desde a década de 1940, concluindo que sempre houve a presença de imigrantes considerados "ilegais", especialmente oriundos da Coreia, Taiwan e China. Assim, ela pontua que há distintas maneiras de se interpretar este período, como por exemplo, dizer que

[...] a economia japonesa não "dependeu" de trabalho estrangeiro em seu período de alto crescimento. Enquanto o trabalho de estrangeiros formou uma proporção substancial na força de trabalho de alguns países europeus durante a década de 1960 e 1970, no Japão este número, em relação ao tamanho total da força de trabalho, era de longe, muito pequeno para dar a ideia de uma noção de "dependência". Mas isto é diferente de dizer que o Japão atingiu seu alto crescimento econômico "sem importar" o trabalho estrangeiro (MORRIS-SUZUKI: 2006, p. 121, tradução nossa). ${ }^{5}$

Esta perspectiva abre caminhos para pensarmos que, ainda que o Japão não tenha "dependido" da força de trabalho do imigrante, sua presença ao longo desse período parece evidente. Os imigrantes dessa época viviam sem documentos e trabalhavam como operários em pequenas empresas locais. Como iremos expor ao longo deste artigo, percebemos que o lócus de trabalho de muitos dos imigrantes irá permanecer o mesmo, situado em funções consideradas não qualificadas dentro da divisão social do trabalho.

A análise de Morris-Suzuki (2006) se mostrou pertinente para a compreensão da história moderna do capitalismo japonês. Assim como esta autora afirma que o imigrante claramente contribuiu para o crescimento do Pós-Guerra, o trabalhador brasileiro no Japão hoje certamente tem um importante papel para a reprodução do capitalismo daquele país. Neste movimento, a atual fase do controle migratório japonês aparece como um aperfeiçoamento e adequação do tipo de controle necessário à atual conjuntura econômica e social e não como um controle regido de forma abstrata ou algo de pouca relevância na história japonesa. Ou seja, só é possível compreender a escolha da "importação" (como 
expressou Morris-Suzuki) de brasileiros como força de trabalho mediante a compreensão socioeconômica da necessidade deste contingente, assim como o lugar que o dekassegui ocupa na sociedade japonesa é fruto da maneira como o Estado japonês historicamente se relaciona com o "outro" manifestado em suas políticas migratórias do sec. XX.

No Pós-Guerra, o investimento maciço em educação, ampliação do contingente disponível para força de trabalho, criação de banco com concessão de capitais e créditos a baixo custo, exportação intensiva de produtos japoneses, foram alguns componentes constitutivos deste cenário. O crescimento do Produto Nacional Bruto (PNB) entre as décadas de 1950-1970 foi em torno de uma extraordinária taxa de $10 \%$, fazendo do Japão a segunda economia mundial em $1968^{6}$.

Não obstante a importância em dar "visibilidade" ao imigrante no Japão, de fato sua proporção é relativamente pequena dentro da população. Entre 1950 a 1988, esse percentual ${ }^{7}$ era em torno de $0,6 \%$ da população. Já na década de 1980, esse número começa a aumentar, chegando no ano de 2010 a 1,67 \% da população do Japão8.

Na década de 1980, a permanência de imigrantes asiáticos (China, Coreia do Sul, Filipinas, Tailândia, Paquistão, Bangladesh, entre outros) começa a se evidenciar (SASAKI, 2000). Esses imigrantes entravam no Japão geralmente com vistos de turistas. E expirada sua validade, permaneciam no país exercendo trabalhos que não exigiam qualificação profissional. Entretanto, o Japão tem como política migratória não aceitar a permanência de trabalhadores imigrantes não qualificados, por isso, nesta época, a maioria deles permanecia indocumentada, trabalhando em empresas de médio e pequeno porte, na construção civil, como também havia a presença de mulheres asiáticas trabalhando na indústria do sexo, como entertainer ou bar hostess ${ }^{9}$ (MORITA e SASSEN, 1994, apud SASAKI, 2000, p.17).

Nessa década de 1980 ocorreu a chamada bolha econômica japonesa, com momentâneas euforias no mercado financeiro, bem como uma taxa de desemprego baixíssima de 2,26\%. Neste período, a carência de força de trabalho, essencialmente na construção civil era preenchida por aqueles imigrantes oriundos dos países asiáticos. Não obstante, a existência de uma população imigrante indocumentada foi algo considerado preocupante pelo governo japonês daquela época. Essa população muitas vezes apresentava características culturais bastante distintas da japonesa e a ela era atribuída a ideia do "perigo do estrangeiro". Essa preocupação é percebida quando consideramos as mudanças feitas pela terceira reforma na Lei de Imigração do Japão (Immigration Control and Refugee Recognition Act) no ano de 1990.

Paralelamente, no Brasil as décadas de 1980 e 1990 apresentaram um novo movimento emigratório, em que o número de brasileiros que emigraram para o exterior aumentou substancialmente. Conforme argumentam Patarra e Baeninger (2006), aconteceu para esses emigrantes que se dirigiam 
principalmente para os países do Primeiro Mundo uma busca por mobilidade social, que se encontrava truncada no Brasil da década de 1980 (chamada década perdida). Os nipo-brasileiros que migraram ao Japão, sejam estes pertencentes à classe trabalhadora brasileira ou alguns poucos oriundos da classe média sentiram perdas significativas em seus padrões de vida, sendo a opção de "tornar-se um imigrante" um dos motivos para o retorno ao país de seus ancestrais, de suas origens.

\section{A dinâmica das políticas de controle de imigração}

As políticas de controle de imigração são diretrizes do governo japonês desenhadas, em uma relação de controle e flexibilização, de acordo com a realidade econômica, social, política, cultural e demográfica do país. Dessa maneira, considerando o processo histórico da imigração no Japão exposto anteriormente, segue-se que o primeiro Plano de Controle de Imigração foi estabelecido em 1951, intitulado Immigration Control Order e influenciado pelos Estados Unidos logo após a Segunda Guerra Mundial. Este plano permitia a entrada de imigrantes como residentes permanentes similar às políticas de imigração americanas (KONDO, 2002).

No entanto, o tipo de permissão de residência permanente para imigrantes nunca fora admitido facilmente pelo Japão e dessa forma, o primeiro plano foi abolido e em seu lugar foi instituído o novo Immigration Control and Refugee Recognition Act em 1982. A reforma se caracterizou pela não permissão do estabelecimento de residência permanente para imigrantes no Japão e pela não admissão de força de trabalho não qualificada, os direitos sociais para imigrantes eram limitados e a política permaneceu sem muitas alterações até sua seguinte reforma em 1990 (KONDO, 2002).

Havia um debate no Congresso japonês naquela época, no tocante à necessidade de diversas reformas referentes à essa Lei de Imigração, pelas constantes mudanças na conjuntura social do país. É por esta razão que sai, em 1990, a terceira reforma do Immigration Control and Refugee Recognition Act, modificando diversos aspectos no que se refere ao controle de migração.

Embora a reforma tenha sido estimulada, em parte, para restringir o excessivo número de imigrantes oriundos dos países asiáticos e para deixar mais restrita a entrada e permanência desses imigrantes, ela passou a permitir a entrada e permanência de imigrantes descendentes de japoneses até terceira geração $\left(\right.$ nikkeis $\left.^{10}\right)$. Além dos nikkeis, também seus cônjuges e dependentes poderiam entrar e permanecer no Japão com um tipo de visto especial que os permitiam exercer qualquer tipo de atividade, inclusive trabalhos sem qualificação profissional (ISHIKAWA, 2009). Esta terceira reforma também permitiu a entrada legalizada de "estagiários" (trainees). Esse tipo de visto de entrada e permanência ${ }^{11}$ no Japão visa a transferência de tecnologias para os países em desenvolvimento, através do treinamento técnico desses imigrantes. 
No entanto, esses imigrantes passaram a compor também a força de trabalho em postos não qualificados no Japão (KONDO, 2002).

Para Kajita, (apud KONDO: 2004, p.2) o governo japonês, ao fazer a reforma da Lei de Imigração de 1990, não tinha intenção direta de estimular a entrada do trabalhador imigrante nikkei. Tratava-se de resolver problemas jurídicos referentes a indivíduos de nacionalidade chinesa e coreana que já residiam no país, como por exemplo, a tentativa de solucionar a questão de legalização da residência da terceira geração de coreanos nikkeis residentes no Japão . Dentro destas reformas, a alteração referente à entrada e permanência de nikkeis de até terceira geração foi a que se desdobrou na possibilidade de os brasileiros e outros latino-americanos descendentes de japoneses entrarem e permanecerem legalmente em solo japonês.

Para o sociólogo japonês Toshio Kondo, ainda que o governo japonês não tivesse o propósito claro de recrutar esses nikkeis como trabalhadores, seria perfeitamente previsível um prognóstico do aumento de trabalhadores nikkeis latino-americanos. $\mathrm{O}$ autor considera ainda que o governo japonês, apesar de prever o trabalho nikkei, não preparou leis ou sistemas referentes à oferta $\mathrm{e}$ procura relativas à força de trabalho imigrante (KONDO, 2004). A rota do trabalhador imigrante nikkei, por não estar juridicamente regulamentada, acaba se tornando algo que estaria permanecendo nos subterrâneos (undergound) da sociedade (KONDO, 2004, p,3), dificultando o acesso às informações da realidade desses trabalhadores.

O caráter excepcional com o qual se trata a questão dos trabalhadores nikkeis nos parece evidente pois, do ponto de vista jurídico, estes trabalhadores não estão no Japão em função de seu trabalho, mas sim em decorrência de sua ascendência (YASUDA, 2010). A entrada desses nikkeis brasileiros, exclusivamente pelo viés étnico, segundo a visão jurídica e formal, parece camuflar o caráter de migração para o trabalho, o que possibilita igualmente a ausência de assistência ou regulamentação específica para este tipo de trabalho imigrante não qualificado que, formalmente inexiste.

Paradoxalmente e a despeito da intenção de não recrutar força de trabalho não qualificada por parte do governo, o número de brasileiros residentes no Japão, que em 1989 era de 14 mil, saltou para 119 mil $^{12}$ em 1991, apenas em um ano após a terceira reforma da Lei Migratória. Kondo $(2004$, p.9) afirma que, na perspectiva do mundo econômico ${ }^{13}$, essa reforma certamente pretendia uma alteração que possibilitaria a entrada de trabalhadores nikkeis latino-americanos sem qualificação profissional no mercado da força de trabalho.

Em nossa compreensão, apesar de sutil, existe uma diferença no discurso que permite a "entrada de nikkeis até terceira geração" para exercerem qualquer tipo de trabalho, mas na prática são sobretudo trabalhos "não qualificados", ao invés de permitir a "entrada de trabalhador sem qualificação". Caso o governo japonês permitisse a entrada de trabalhadores não qualificados, haveria a necessidade de abrir seu território para as mais diversas nacionalidades, muito além dos nikkeis. 
Essas mudanças na política de controle de imigração responderam sobretudo à uma necessidade nas questões do desenvolvimento econômico do Japão. Em nossa compreensão, as mudanças ocorridas na reforma da política de controle migratório se assentam em bases materiais muito particulares, mesmo que, do ponto de vista do discurso político, essa base material não se apresente de maneira cristalizada.

\section{A informalidade das relações de trabalho no Japão: 0 lugar do imigrante dekassegui}

Não parece ser coincidência que, no mesmo período em que foi instituída a terceira reforma da política de controle de imigração, o Japão começava a encarar também o crescimento do fenômeno da informalidade no mundo do trabalho. Esse fenômeno vem crescendo gradativamente desde o final da década de 1980 e especialmente a partir da década de 1990. As relações de trabalho consideradas informais, as quais nos referimos, têm como critério a abordagem utilizada no Japão em que os trabalhadores ocupados e empregados (excluídos os empregadores) se dividem em: trabalhadores de tipo efetivo/regular (seiki kouyou 正規雇用) e não efetivo/irregular (hiseiki koyou非正規雇用) sendo este segundo marcado pela informalidade.

Os trabalhadores de tipo efetivo são aqueles diretamente contratados pela empresa por tempo indeterminado e usufruindo de todos os direitos sociais conquistados. Sua característica principal é a estabilidade no trabalho e seu reflexo nas condições sociais de vida oriundas da proteção social. Sua figura mais representativa é o chamado salaryman (sarariiiman, サラリーマン), o trabalhador homem white-collar.

Trabalhadores de tipo não efetivo/irregular podem ser subdivididos em diferentes tipos de relações contratuais como: temporário (part-time job, パ ートタイム), arubaito (アルバイト outra modalidade de trabalho temporário, geralmente de duração mais curta), terceirizados (haken shain, 派遣社 員), trabalhador por contrato de tempo determinado (keiyaku shain，契約社 員), entre outras novas relações contratuais como trabalhador de tipo diário ( hiyatoi, 日雇い), entre outros. Sua principal característica é a instabilidade de contratos de trabalho, direitos sociais historicamente conquistados sendo tendencialmente reduzidos, se comparado ao trabalhador efetivo.

Segundo dados do Ministério da Saúde, Trabalho e Bem-Estar Social do Japã ${ }^{14}$, a evolução do trabalho informal no Japão vem crescendo de maneira significativa. Em 1985, 16,4\% dos trabalhadores empregados se enquadravam na categoria de trabalhador de tipo não efetivo (hiseki), em contraste com $83 \%$ da população como trabalhadores de tipo efetivo (seiki). Em 1990, a proporção dos trabalhadores não efetivos passou para $20,2 \%$, chegando a mais de 35 \% em 2013. 
Os imigrantes dekasseguis estão inseridos no mercado de trabalho japonês, sobretudo na informalidade, com contratos de trabalho flexíveis, poucos direitos trabalhistas e sociais assegurados, bem como exercem longas jornadas de trabalho e têm alta rotatividade de empregos. De modo geral, não existem muitos dados abrangentes e detalhados acerca do mercado da força de trabalho imigrante residente no Japão. Segundo as referências que obtivemos ${ }^{15}$, em 2013 eram 717 mil trabalhadores imigrantes legalmente cadastrados, dos quais $13,3 \%$ eram brasileiros (95 mil trabalhadores cadastrados). Nesse mesmo ano, dos $181 \mathrm{mil}$ imigrantes brasileiros registrados no Japão, cerca de 160 mil possuíam vistos de permanência pela sua ascendência nikkei como: residência permanente (eijyuusha), residência temporária (teijyuu-sha) entre outros. Essa condição caracteriza a estadia por laços de consanguinidade ${ }^{16}$, isto é, a entrada e permanência não ocorreram por vistos para exercer trabalhos técnicos, antes, o trabalho de brasileiros no Japão é constituído por trabalhos considerados não qualificados.

Os setores que mais contratam brasileiros são os de autopeças para indústria automobilística, seguido pelas fábricas manufatureiras de componentes eletroeletrônicos, e as fábricas de "marmitex" (bentou-ya) ${ }^{17}$ respectivamente (HIGUCHI, 2010). O brasileiro imigrante, com exceção dos que trabalham em estabelecimentos voltados para a população brasileira, trabalha em fábricas, ou kaishas $^{18}$ majoritariamente de médio e pequeno porte, que empregam até 300 trabalhadores. Suas condições de trabalho são extremamente precarizadas, com longas jornadas de trabalho, alta rotatividade mediante processos de trabalho repetitivos. As relações de trabalho são em sua maioria informais, com contratos de trabalho de curta duração, seguridades sociais tendencialmente ausentes, regidos pelo modelo flexível, isto é, com pouca estabilidade, o que implica em dificuldades de planejamento e perspectivas para o futuro.

Dos trabalhadores brasileiros em 2013, 56,5\% trabalhavam na indústria e $26,7 \%$ em diversos ramos de serviços ${ }^{19}$. Na indústria, $55 \%$ trabalhavam como terceirizados ou na forma de empreitada. Isto não significa que o restante (45\%) eram trabalhadores dekasseguis efetivos das empresas, mas sim, possuíam contratos por tempo determinado (keiyaku shain) com a empresa, ou eram arubaito, entre outras modalidades marcadas pela informalidade. Dos trabalhadores imigrantes oriundos dos países que compõe o G8 (grupo dos oito países mais poderosos do mundo) ${ }^{20}$, quase metade (45\%) trabalha na área da educação, sendo pouquíssimos os trabalhadores operários entre os imigrantes destes países.

Verificamos aqui uma divisão bastante clara no que tange a nacionalidade em relação aos trabalhos qualificados e não qualificados. Podemos considerar que estes imigrantes residentes no Japão, não chegam ao país e lá se estabelecem no mercado de força de trabalho de forma aleatória. A divisão social do trabalho opera antes mesmo de sua chegada ao território, pois a entrada no Japão já o classifica de acordo com a função que ele irá exercer em território japonês. 
A crise econômica de 2008 parece ter sido o momento oportuno para explicitar diversas relações de trabalho dos dekasseguis. Especialmente no seu auge foi percebida uma queda abrupta no salário, redução dos dias e da jornada de trabalho, fim das horas extras, como também a demissão em massa em alguns setores nos quais os dekasseguis se inserem, tais como o automobilístico e o eletroeletrônico. Nesse período, relatos de brasileiros que não conseguiam suprir suas necessidades básicas de subsistência, assim como nikkeis que perderam a moradia não foram raros. A conclusão que se chega é de que as condições e relações de trabalho dos dekasseguis, podem, a qualquer momento, se transformar, mostrando-se frágeis por justamente não haver uma base consolidada e estável de sua inserção no mercado de trabalho.

A partir da crise de 2008, somado ao Grande Terremoto de Tohoku em 2011, o reflexo na economia tem sido bastante severo, as políticas de controle migratório também começaram a refinar a já existente seletividade no controle migratório, mesmo entre os imigrantes que já residiam no país de forma legalizada.

\section{As políticas migratórias atuais: entre os imigrantes desejáveis e os indesejáveis}

Após a emenda na Lei de Imigração de 1990 (terceira reforma do Immigration Control and Refugee Recognition $A c t^{21}$ ), foi criado um 'Plano Básico para Controle da Imigração' [PBCl]. Segundo consta em seus documentos, o $\mathrm{PBCl}$ foi criado para estabelecer as diretrizes básicas do Japão sobre o controle de imigração e aumentar a transparência dessa administração tanto para o próprio Japão, como para os países estrangeiros, além de implementar medidas coerentes com essas diretrizes (MINISTRY OF JUSTICE. 2nd. BASIC PLAN FOR IMMIGRATION CONTROL,[PBCI] 2000). Esse documento formulado pelo Ministério da Justiça do Japão ficou pronto em 1992 e se tornou o '10 Plano Básico de Controle de Imigração'. Após a publicação de sua segunda edição no ano 2000. Uma terceira edição foi publicada em 2005, e a quarta edição em 2010.

A primeira edição do $\mathrm{PBCl}$ tinha como objetivos "facilitar a aceitação de estrangeiros" ao mesmo tempo em que propunha a "recusa dos estrangeiros desfavoráveis" sendo essas as duas principais tarefas que cumpririam os Planos Básicos (MINISTRY OF JUSTICE. 2nd. BASIC PLAN FOR IMMIGRATION CONTROL, 2000). De acordo com essa declaração por parte do governo japonês, percebemos que a política migratória, apesar de propor a aceitação de imigrantes, deixa claro que não é qualquer imigrante, senão, o profissional qualificado. Isso, mesmo em período de grande desenvolvimento econômico. Por 'estrangeiros desfavoráveis' entende-se os imigrantes sem qualificação profissional, aqueles que entram e permanecem no Japão de forma indocumentada, entre outros não previstos pela lei. 
Nosso questionamento aqui seria o de pensar qual é o lugar que ocupa o imigrante dekassegui na política de controle migratório. Consideramos que ele esteja situado no limiar justamente entre o imigrante desejável e o indesejável. Pois, apesar de estar legalmente no Japão, ocupam postos de trabalho sem qualificação profissional, aumentando uma população de imigrantes não qualificados, situação que contraria o que o Japão espera do ponto de vista da imigração.

Dessa maneira, segue-se que a segunda edição do PBCI no ano 2000 mantém inalteradas essas diretrizes, mas propõe flexibilizações e medidas a serem propostas por questões relativas: i) ao rápido processo de internacionalização e globalização provocada pelo avanço das telecomunicações, transporte e liberalização dos sistemas econômicos, ii) ao processo de rápido envelhecimento da população com a queda da fecundidade e com a previsão de que a população japonesa começaria a decrescer na década de 2000, iii) a partir dos dois pontos anteriores, lidar com a questão de uma maior abertura do Japão à imigração como parte de um processo de maturidade social, mas considerando também seu histórico de percepção do povo japonês à essa questão, iv) à segurança nacional que pode ser colocada em risco com o grande número de imigrantes indocumentados ${ }^{22}$, pois os crimes cometidos por imigrantes no Japão em anos anteriores foram considerados um sério problema para a sociedade japonesa (MINISTRY OF JUSTICE. 2nd. BASIC PLAN FOR IMMIGRATION CONTROL, 2000).

Essa segunda edição do $\mathrm{PBCl}$, lançada no ano 2000, apresenta maior preocupação do Japão em flexibilizar a política de controle migratório por questões relativas às dinâmicas econômicas e demográficas do país. Em relação a dinâmica demográfica, o debate se inicia com a queda da fecundidade no Japão, que ocorreu de forma rápida e intensa a partir de meados do século XX. Embora as políticas migratórias japonesas e suas reformas tenham sua origem muito mais ligada a contextos e conjunturas socioeconômicas e políticas (pósguerra principalmente) do que à própria dinâmica demográfica, a estrutura da população se apresenta como mais um fator de mudanças.

O desafio na entrada do século XXI para as políticas de controle migratório parece ser também o de considerar seu planejamento visando amenizar as consequências que surgiram da queda da fecundidade e consequente transição da estrutura etária no Japão ${ }^{23}$. Nesse sentido, os principais desafios estão relacionados ao envelhecimento da população com a diminuição relativa da população em idade ativa, bem como a contínua queda da fecundidade que acentua essa tendência e acarreta em um crescimento negativo da população e seu declínio. A queda da fecundidade acarreta em uma mudança na estrutura etária da população, com um estreitamento da base (população de 0 a 14 anos de idade) devido ao menor número de nascimentos. Em médio e longo prazo isso acarreta em um envelhecimento relativo e absoluto da população.

O Japão ainda apresenta um diferencial por possuir uma das maiores expectativas de vida do mundo. Em 2008 para as mulheres era de 86,05 anos 
de vida ao nascer e para os homens de 79,29, a maior do mundo entre as mulheres e a quarta maior entre os homens (SUZUKI, 2009). Considerando a dinâmica demográfica japonesa, sua estrutura etária já se apresenta com uma maior proporção de idosos do que de crianças. Essa diferença nas proporções dos grupos etários tem como um dos principais problemas a diminuição da população em idade ativa. A queda da população em idade ativa implica em dificuldade de cobertura dos postos de trabalho, principalmente aqueles não qualificados.

A cobertura da escassez desse tipo de mão de obra é uma das preocupações das políticas de imigração da maioria dos países desenvolvidos do Ocidente, que apresentam o perfil demográfico semelhante ao do Japão (TEITELBAUM, 2004). No entanto, essa não foi a principal motivação das formulações de políticas de controle de imigração do Japão até pouco tempo. Mas, em conflito com os condicionantes de ordem demográfica, está a preocupação com a abertura para imigrantes com um perfil não desejado pelo Estado (e pela população japonesa, segundo o discurso oficial do país relatado nos Planos Básicos). Seria este o perfil de imigrantes não qualificados, etnicamente muito "diferentes" e o que são vistos ainda, sobretudo, como o "perigo estrangeiro".

A terceira edição do $\mathrm{PBCl}$, publicada em 2005, acentua a característica da política migratória que é foco de nossa análise, qual seja, propor uma maior aceitação e melhores condições de entrada e permanência no Japão de estrangeiros "que são bem-vindos ao país", ou seja qualificados - os desejáveis - ao passo que restringe e formulam planos de maior controle aos imigrantes que são considerados os indesejáveis - imigrantes não qualificados, que tendem a permanecer no Japão trabalhando na informalidade depois de expirado seu visto de permanência, e aos quais são atribuídos o perigo e a criminalidade no Japão ${ }^{24}$.

Parece haver nesse ponto uma contradição entre as declarações formais do que se espera com as políticas de controle migratório no Japão, e as necessidades do mundo do trabalho, bem como da dinâmica demográfica japonesa. Se por um lado, não se deseja a permanência de trabalhadores sem qualificação profissional no país, do ponto de vista de abertura do país aos imigrantes. Por outro, há uma necessidade de ocupação dos postos de trabalho que não exigem qualificação profissional. O dekassegui é a figura que está no centro dessa contradição sendo afetado do ponto de vista do trabalho, pois se encontra em postos de trabalho não qualificados e na informalidade e enquanto imigrante, sua entrada e permanência é controlada do ponto de vista formal e legal na sociedade japonesa.

Entre a publicação dos terceiro e quarto $\mathrm{PBCl}$, ocorreu a inesperada crise econômica de 2008. Esse momento trouxe à superfície as diversas condições vulneráveis da inserção dos imigrantes na sociedade japonesa, tanto no mercado de trabalho, como no relativo aos equipamentos sociais elementares (habitação e educação, por exemplo). 
Nesse período, um dos exemplos da flexibilidade do controle migratório em face da dinâmica do mercado de trabalho foi a medida emergencial de "auxílio retorno" (Programa de Assistência de Retorno à Pátria). Essa medida foi uma proposta do governo japonês que concedia aos imigrantes uma quantia de 300 mil yens (cerca de 3 mil dólares) para custeio das passagens de retorno aos brasileiros que se encontravam desempregados ${ }^{25}$.

A desestabilização do esquema em que o dekassegui estava inserido - legal do ponto de vista jurídico no que toca a imigração e informal e não qualificado no mercado de trabalho - trouxe à tona o que o discurso do governo japonês não queria admitir em suas publicações em relação à imigração dekassegui: que se trata de uma imigração de trabalhadores que estão inseridos, sobretudo, no setor industrial exercendo trabalhos sem qualificação profissional. Esse "reconhecimento" da realidade do imigrante nikkei no Japão aparece somente na quarta edição do PBCl publicada em 2010:

No passado, eles apoiaram a economia local por realizarem trabalhos no setor industrial, onde havia uma escassez de mão de obra, e através da sua vitalidade, contribuíram para o desenvolvimento da economia japonesa, e, além disso, trouxeram uma cultura diversa e vitalidade às comunidades locais. Por outro lado, no entanto, as diferentes origens culturais, valores e costumes, combinado com inadequada habilidade do idioma japonês causou, pelo menos, algum atrito e conflito com as comunidades locais. Em particular, desde o segundo semestre de 2008, em meio a uma rápida crise econômica, os problemas relativos ao emprego, habitação e educação dos filhos de estrangeiros descendentes de japoneses, que estavam trabalhando em instáveis condições de trabalho, como empregados através de empreitada ou de contrato de trabalho, tem piorado. (MINISTRY OF JUSTICE: 2010. p, 27) ${ }^{26}$

A quarta edição publicada em 2010, no entanto, mantém os objetivos iniciais dos $\mathrm{PBCl}$; nesta edição, as mudanças observadas e medidas propostas foram relativas: i) à era de declínio populacional japonês e principalmente o declínio da população em idade produtiva, e as instabilidades econômicas acarretadas pela crise econômica internacional de 2008; ii) à introdução de um novo sistema de gestão de residência aos estrangeiros, uma vez que há um crescimento dessa população no Japão e maior diversidade de suas atividades; iii) à questão dos refugiados, tendo-se em conta um aumento do número de pedidos de reconhecimento (MINISTRY OF JUSTICE. 4th BASIC PLAN FOR IMMIGRATION CONTROL, 2010).

As políticas continuam com seu caráter de seletividade de ascendência japonesa e qualificação da força de trabalho, no entanto, procuram alargar o 
número de entrada desses imigrantes "favoráveis" para o Japão com facilidades para retirada de vistos de permanência e estabilização no país. Com o novo sistema de residência, também a temporalidade dos vistos de permanência foi alterada. O prazo máximo de permanência foi alterado de três para cinco anos. No entanto, são cobradas da população residente, novos requisitos para que permaneçam no país. A exigência do conhecimento do idioma japonês para conseguir emprego depois da crise foi uma das principais mudanças sentidas pelos imigrantes que permaneceram no Japão ${ }^{27}$.

\section{Considerações finais}

O Japão apresenta uma história de imigração que vai desde um total isolamento e caminha para aberturas graduais na recepção de população imigrante, até os dias atuais. Esse movimento está estreitamente relacionado com as conjunturas econômicas, sociais, políticas e à dinâmica demográfica do país. A entrada e permanência de imigrantes brasileiros no Japão, na condição de dekasseguis a partir da década de 1990, é uma questão que, analisada do ponto de vista das políticas de controle migratório e da inserção destes no mercado de trabalho, demonstra uma situação aparentemente contraditória. Se por um lado, não aceitam a entrada e permanência de imigrantes sem qualificação profissional, por outro, necessitam desse contingente, principalmente em períodos de intenso desenvolvimento econômico.

No entanto, ao aceitar os imigrantes nikkeis de até terceira geração, o Japão consegue resolver o empecilho de, na prática, suprir a força de trabalho não qualificada contando com os estrangeiros dekasseguis, sem precisar, em teoria, abrir seu território para força de trabalho sem qualificação. Selecionando assim a força de trabalho necessária para cada finalidade não precisa se preocupar com um possível fluxo de imigrantes considerados 'indesejáveis'.

As políticas migratórias atuais, principalmente no período pós-crise de 2008 procuram manter os estrangeiros "desejáveis" e barrar ainda mais a entrada dos "indesejáveis". Através da crise, pode-se observar que, não obstante a situação jurídica do dekassegui, sua relação de trabalho é sobremaneira instável. Até mesmo o salário, fator que sempre fora relativamente estável e com um patamar razoável, se mostrou flexível em épocas de crise. O Programa de Assistência de Retorno à Pátria, neste caso, demonstrou que, quando há a necessidade de repelir seus trabalhadores imigrantes, em épocas de crise, por exemplo, a legislação estará prontamente preparada para qualquer modificação necessária. A utilização do dinheiro público para retorno dos nikkeis pode demonstrar a preferência em que dekasseguis façam o caminho de volta, ao invés de engrossar a fila do desemprego no Japão.

Chamar esse auxílio de volta ao país de origem de "retorno à pátria" é evidenciar que ali, definitivamente não é o lugar do imigrante. Esta denominação de uma política social estatal explicita que o nikkei não pertence a pátria japonesa, 
e portanto o imigrante será sempre visto dessa forma específica, discriminada. Ele é incômodo e deslocado no espaço social que ocupa (SAYAD, 1998). Ainda que legalmente o imigrante nikkei seja aquele que tem a sua estadia permitida e necessária, suprindo assim, a carência do mercado da força de trabalho, a ele não são oferecidas as condições de vida que proporcionem uma estabilidade de permanência. Para ele resta, portanto, um lugar à margem do todas as seguridades sociais conquistadas e auferidas para parte dos nacionais, incorrendo em uma estadia que carrega em si ambiguidades e contradições próprias do fenômeno migratório. O dekassegui é, ao mesmo tempo, desejado e indesejado (xenofobia), necessário e desnecessário quando convier (crise econômica), socialmente deslocado, incômodo, mas permanentemente presente, bem como parte constitutiva da classe trabalhadora japonesa.

\section{Notas}

1 - Uma versão preliminar deste trabalho foi apresentada no XXIX Congreso de la Asociación Latinoamericana de Sociología (ALAS), Chile, Setembro/Outubro de 2013.

2 - 鎖国. Os dois ideogramas (kanji) se referem a corrente e país, em uma tradução livre como país acorrentado.

3 - 内地雑居, numa livre tradução, residência mista na ilha.

4 - As configurações das políticas de controle migratório a partir deste período serão expostas no próximo tópico deste trabalho.

5 - [...] the Japanese economy did not "depend" on foreign labor in the high-growth era. While foreign workers formed a substantial proportion of the work force in some European countries during the 1960s and 1970s, in Japan their number, in relation to the total size of the work force, was far too small to bear the weight of notions like "dependence". But this is different from saying that Japan achieved its high growth "without importing" foreign workers.

6 - Posição ultrapassada pela China em 2010.

7 - Exclui-se deste número os indocumentados.

8 - Dados extraídos do Ministério da Justiça do Japão (2010).

9 - A presença de trabalhadoras asiáticas na indústria do sexo é até hoje muito frequente no Japão.

10 - A palavra nikkei é uma abreviação do termo em japonês nikkeijin que significa "pessoas de descendência japonesa".

11 - Sob esse status de permanência, é permitido um ano para estagiários e dois para técnicos, totalizando o máximo de três anos de permanência no Japão sob esse tipo de visto.

12 - Departamento de Controle de Imigração do Ministério da Justiça do Japão (2001) (apud MELCHIOR, 2008).

\section{Keizaikai- 経済界}

14 - Ministry of Health, Labour and Welfare (Kousei Roudoushō) http://www.mhlw.go.jp/ seisakunitsuite/bunya/koyou_roudou/part_haken/dl/hiseiki_kanren1.pdf 
15 - http://www.mhlw.go.jp/file/04-Houdouhappyou-11655000-Shokugyouanteikyokuhaken yukiroudoutaisakubu-Gaikokujinkoyoutaisakuka/0000036118.pdf

16 - Dados estatísticos Ministério da Justiça do Japão. Sobre o controle de estrangeiros cadastrados no ano de 2013: (Fonte: http://www.e-stat.go.jp/SG1/estat/List. do?lid=000001118467)

17 - Este tipo de "marmitex" (bentou), fabricados em escala industrial é largamente consumido em todo o território nacional, sua venda ocorre em supermercados, lojas de conveniência entre outros estabelecimentos e consumido de forma cotidiana, principalmente por trabalhadores em seus almoços no Japão.

18 - Kaisha, em japonês significa fábrica, empresa, ou companhia. Os dois ideogramas (kanji) que constituem esta palavra 会社 significam, em tradução livre, respectivamente encontro e sociedade, isto é, tem um sentido de o lugar de se encontrar na sociedade. É muito comum em japonês a expressão "Vou ao kaisha", "Voltei do kaisha" ao invés de "Vou trabalhar" ou "Voltei do trabalho" onde o substantivo kaisha é usado para designar o trabalho em seu sentido amplo

19 - Fonte: Ministry of Health, Labour and Welfare (Kousei Roudoushō) http://www.mhlw. go.jp/file/04-Houdouhappyou-11655000-Shokugyouanteikyokuhakenyukiroudoutaisaku bu-Gaikokujinkoyoutaisakuka/0000036118.pdf

20 - G8 - Grupo dos oito países mais poderosos do mundo. Sua composição original era formada por: Estados Unidos da América (EUA), Alemanha, Inglaterra, Japão, Itália, França, Canadá e Rússia. Sob a alegação de envolvimento indevido em conflitos bélicos no Leste Europeu em 2014 e 2015, a Rússia foi excluída do G8 em março de 2015. A partir daí, o então "G8" passou a se cognominar G7 - Grupo dos sete países mais poderosos do mundo. Nota do Editor.

21 - Ordem no. 319 de 1951, alterada em 1989, a partir de então referida como Immigration Control Act.

22 - Em 2000 havia cerca de 270 mil estrangeiros indocumentados residentes no Japão, se forem somados os que entraram irregularmente no Japão, esse número pode ser muito maior (2nd. BASIC PLAN FOR IMMIGRATION CONTROL, 2000)

23 - Essa queda rápida e intensa que aconteceu no Japão poderia ser explicada como uma mistura de aderência espontânea ao sistema europeu e a políticas de população do pósguerra. A derrota na guerra teria invertido as políticas natalistas e o apelo ao aumento populacional como argumento de conquista do Estado Imperial japonês. O código civil aplicado pelos ocupantes americanos em 1947 instituiu a igualdade legal de gênero, a reversão do natalismo governamental, e, em 1948, uma nova 'Lei de Proteção Eugênica' que substituiu a lei natalista e legalizou o aborto. Em 1950, houve um treinamento, promovido pelas autoridades de saúde pública, de consultores em contracepção com reuniões de educação de massas em contracepção. Com isso as práticas contraceptivas espalharam-se rapidamente entre os casais japoneses (THERBORN, 2006).

24 - A terceira edição do Plano Básico tinha como diretrizes: i) propor medidas visando estabelecer o Japão como um país turístico; ii) aceitar de forma mais aberta os trabalhadores altamente qualificados e os de campos profissionais ou técnicos, considerando que a população produtiva no Japão já começava a diminuir; iii) o estabelecimento de uma meta em reduzir pela metade o número de estrangeiros indocumentados no Japão até o ano de 2008, uma vez que esse número se manteve alto para seus patamares, causando problemas sociais e de segurança (3rd. BASIC PLAN FOR IMMIGRATION CONTROL, 2005).

25 - Sobre as medidas governamentais emergenciais desse período: SHISHITO, K.T.; SHISHITO, F. A. (2013). O impacto da crise econômica de 2008 sobre o movimento 
dekassegui. In: BAENIGER, Rosana; DEDECCA, Claudio Salvadori. (Org.). Processos Migratórios no Estado de São Paulo: estudos temáticos. 1ed.Campinas: Nepo/Unicamp, v. 10 , p. $509-522$.

26 - Tradução livre, no original: "in the past they supported the local economy by engaging in field work in the manufacturing sector where there was a labor shortage and, through their vitality, contributed to the development of the Japanese economy, and furthermore, brought a diverse culture and vitality to the local communities. On the other hand, however, the different cultural backgrounds, values and customs, combined with inadequate Japanese language skills caused, at the very least, some friction and conflict with the local communities. In particular, since the latter half of 2008, amid a rapidly worsening economic situation, the problems pertaining to the employment, housing and education of the children of foreign nationals of Japanese descent, who were working in unstable employment conditions such as being employed through dispatch or contract work, have been worsening." (4th Basic Plan for Immigration Control, 2010. P.27).

27 - Informações obtidas através de entrevistas realizadas com brasileiros dekasseguis residentes no Japão e retornados nas pesquisas de mestrado de ambas as autoras.

\section{Referências}

ASADA, Hideko. Ethnic Relationships between Japanese-Brazilians and Japanese: Examining factors apt to foster “living together" (日系ブラジル人と日本人の民族関係 : 共生の 視点から) Intercultural communication studies, n. 4, 2001.

HIGUCHI, Naoto. Keizai kiki to Zainichi Burajirujin, Nani ga tairyou shitsugyou, kikoku wo motarashita noka. (経済危機と在日ブラジル人、何が大量失業, 帰国をもたらし たのか) Oohara Shakai Mondai Kenkyuu sho Zasshi, n. 622/8, 2010. Disponível em: <http://oohara.mt.tama.hosei.ac.jp/oz/622/622-05.pdf> Acesso em 15 de jul. /2011.

ISHIKAWA, Eunice Akemi. Brasileiros no Japão: de temporários à permanentes. in Relatório: Coexistência Multicultural na Província de Shizuoka - Análise dos Resultados da Pesquisa Sobre as Condições de Trabalho dos Estrangeiros na Província de Shizuoka, pp.74-85. Shizuoka, 2009.

KONDO, Atsushi. Development of Immigration Policy in Japan. in Asia and Pacific Migration Journal, vol. 11, no. 4, pp. 415-436, 2002. Disponível em: http://www.smc.org.ph/ administrator/uploads/apmj_pdf/APMJ2002N4ART2.pdf Acesso em 12 jul./2011.

KONDO, Toshio. Nikkei Burajirujin no Shuurou to Seikatsu （日系ブラジル人の就労と生 活）. Bukkyou Daigaku, Shakai Gakubu Ronshuu, n.10 pg.1-18, 2004. Disponível em: http://archives.bukkyo-u.ac.jp/rp-contents/SO/0040/SO00400L001.pdf Acesso em 1 de jun. de 2012.

MELCHIOR, Lirian. Redes sociais e migrações laborais: múltiplas territorialidades. A constituição da rede nipo-brasileira em Ourinhos (SP) e no Japão, Tese (Doutorado em Geografia). FCT-UNESP. Presidente Prudente, 2008.

MINISTRY OF JUSTICE. Basic plan for immigration control. 2nd. Edition, 2000. Disponível em: www.moj.go.jp/ENGLISH/information/bpic2nd-01.html Acesso em 12 de jul./2011

. Basic plan for immigration control. 3nd. Edition, 2005. Disponível em: http://www.moj.go.jp/ENGLISH/information/bpic3rd-02.html Acesso em 05 de ago./2011. 
Basic plan for immigration control. 4nd. Edition, 2010. Disponível em:

http://www.immi-moj.go.jp/seisaku/keikaku_101006_english.pdf

Acesso em 10 de jan./2013.

MORRIS-SUZUKI, Tessa. Invisible Immigrants: Undocumented Migration and Border Controls in Early Postwar Japan, The Journal of Japanese Studies, v. 32, n.1, Winter, pp. 119-153, 2006.

http://muse.jhu.edu/journals/jjs/summary/v032/32.1morris_suzuki.html Acesso em 1 de jun/2012.

ODA, Ernani. Interpretações da "cultura japonesa" e seus reflexos no Brasil. Revista Brasileira de Ciências Sociais, v. 26, n. 75, p. 103-117, 2011.

PATARRA, Neide; BAENINGER, Rosana. Mobilidade espacial da população no Mercosul: metrópoles e fronteiras. Revista Brasileira de Ciências Sociais, São Paulo , v. 21, n. 60, p. 83-102, fev., 2006.

http://www.scielo.br/scielo.php?pid=S0102-69092006000100005\&script=sci_arttext Acesso em 10 de ago/ 2012.

SASAKI, Elisa. Dekasseguis: trabalhadores migrantes nipo-brasileiros no Japão. Campinas. UNICAMP. Núcleo de Estudos de População, 2000.

SAYAD, Abdelmalek. Imigração ou os Paradoxos da Alteridade. Edusp, 1998.

SHISHITO, Katiani Tatie ; SHISHITO, Fábio Akira. O impacto da crise econômica de 2008 sobre o movimento dekassegui. In: BAENIGER, Rosana; DEDECCA, Claudio Salvadori. (Org.). Processos Migratórios no Estado de São Paulo: estudos temáticos. 1ed.Campinas: Nepo/Unicamp, v. 10, p. 509-522, 2013.

SUZUKI, Toru. "The latest development in Population of Japan" The Japanese Journal of Population 7(1): p. 87-90, 2009.

Disponível em:

http://www.ipss.go.jp/webjad/webjournal.files/population/2009_4/Web\%20 Journal_05.pdf

Acesso em 15 de jun/2010.

TAKAHASHI, Shigesato. "Demographic Investigation of the Declining Fertility Process in Japan" in The Japanese Journal of Population vol.2 n.1, 2004.

Disponível em:

http://www.ipss.go.jp/webjad/webjournal.files/population/2004_3/Takahashi2004mar.pdf Acesso em 15 de jun./2010.

TEITELBAUM, Michael, S. "Western Experiences with International Migration in the Context of Population Decline" The Japanese Journal of Population, 2 (1): 29-40, 2004. Disponível em:

http://www.ipss.go.jp/webj-ad/webjournal.files/population/2004_3/ michael2004mar.pdf

Acesso em 15 de jun./2010.

THERBORN, Goran. Casais, bebês e estados. In: THERBORN, Göran. Sexo e Poder: A família no mundo, 1900-2000. São Paulo: Editora Contexto, 2006.

YASUDA, Kouichi. Rupo, Sabetsu to hinkon no gaikokujin roudousha (ルポ，差別と貧困 の外国人労働者). Tokyo Koubunsha shinsho, 2010. 


\section{RESUMO}

Este artigo analisa os condicionantes sociais da relação entre o Estado japonês e o imigrante, a fim de problematizar principalmente duas questões: qual foi (qual é) o papel do Estado japonês em relação à recepção dos imigrantes em seu país? Como ocorre a inserção destes no mercado da força de trabalho? Para responder a tais indagações, consideramos as reflexões sobre: i) as principais políticas migratórias de abertura ou restrição aos imigrantes durante os séculos XX e XXI; ii) a relação do mercado da força de trabalho com estas políticas destinadas aos imigrantes e iii) por fim, como ocorreu a inserção destes imigrantes no mercado de trabalho japonês.

Palavras-chave: migração internacional - políticas migratórias - mercado de trabalho

\section{ABSTRACT}

This article analyzes the social conditions of the relationship between the Japanese State and immigrant, to discuss mainly two questions: what was (which is) the role of the Japanese State in relation to the reception of immigrants in their country? As the inclusion of these in the market of the workforce? To answer such questions, we consider the reflections on: i) the main migratory policies or opening restriction on immigrants over the centuries XX and XXI; ii) the market regarding the workforce with these policies to immigrants; and iii) finally, as was the inclusion of these immigrants in the Japanese labor market.

Key words: International migration - migration policies - labor market 